\title{
Electrical Conductivity Measurement of Fayalite Under Shock Compression up to $56 \mathrm{GPa}$
}

Tsutomu Mashimo,' Ken-IChi Kondo, and AKIRA Sawaoka

Research Laboratory of Engineering Materials, Tokyo, Institute of Technology, Tokyo 152, Japan

YASUHIKO SYONO ${ }^{2}$ AND HUMIHIKO TAKEI

Research Institute for Iron, Steel and Other Metals, Tohoku University, Sendai 980, Japan

Thomas J. AHRENS

Seismological Laboratory, California Institute of Technology, Pasadena, California 91125

\begin{abstract}
The electrical conductivity measurements of single-crystal fayalite are performed under shock wave compression in the pressure range 19.5-56 GPa. The electrical conductivity under shock compression increases by a factor of more than $10^{10}$ from 0 to $40 \mathrm{GPa}$. Over the range $19.5-42 \mathrm{GPa}$ the specific conductivity $\sigma$ can be closely described by $\log _{10} \sigma(\mathrm{S} / \mathrm{m})=-4.65+0.15 P(\mathrm{GPa})$. The conductivity versus pressure relation at room temperature is calculated by using measured values of the activation energy to correct the high-temperature shock data to room temperature. After the effect of temperature is removed, the increase in conductivity with pressure approximately agrees with that measured under static pressure using a diamond anvil cell by Mao and Bell. Above pressures of $\sim 42 \mathrm{GPa}$ the conductivity remains at a relatively high level of $\sim 100 \mathrm{~S} / \mathrm{m}$ from 40 to $55 \mathrm{GPa}$.
\end{abstract}

\section{INTRODUCTION}

Olivine, $(\mathrm{Mg}, \mathrm{Fe})_{2} \mathrm{SiO}_{4}$, is one of the main constituents of the earth's mantle. Its physical properties such as electrical conductivity are important because of the availability of conductivity measurements of the earth's mantle, which are carried out in inversion of magnetic induction data. A number of electrical conductivity measurements on olivine have been carried out, and various factors affecting the conductivity are summarized by Duba and Nicholls [1973] and Shankland [1975]. Iron and other transition metal ion content, oxygen fugacity, and temperature are among the more important variables, whereas pressure affects conductivity to a lesser degree.

The electrical conductivity and the absorption spectra of the olivine and spinel forms of $\mathrm{Fe}_{2} \mathrm{SiO}_{4}$ have previously been measured under static pressure up to $30 \mathrm{GPa}$ using a diamond anvil apparatus by Mao and Bell [1972]. The electrical conductivity of olivine increases by a factor of more than $10^{5}$ over this pressure range, and this increase was explained from consideration of the red shift of the optical absorption edge as being due to $\mathrm{Fe}^{2+}-\mathrm{O}^{2-}$ charge transfer processes. Very recently, electrical conductivity measurements of natural olivines were carried out up to $40 \mathrm{GPa}$ by using a shock wave technique, and a considerable increase in conductivity was reported [Schulien et al., 1978]. The present study was carried out concurrently with that of Schulien et al. [1978] to relate the conductivity measurements under shock condition to the transport properties of the earth's mantle.

In the present study the measurements of the electrical conductivity of pure fayalite were extended to pressures up to 56 $\mathrm{GPa}$ using shock compression techniques.

\footnotetext{
${ }^{1}$ Now at Faculty of Engineering, Kumamoto University, Kumamoto 860, Japan.

${ }^{2}$ Author responsible for correspondence.

Copyright (c) 1980 by the American Geophysical Union.
}

\section{ExPERIMENTAL Procedures}

Since the electrical properties of fayalite are sensitive to stoichiometry, pure synthetic single crystals were grown using the floating zone method under controlled oxygen fugacity (partial pressure of oxygen, $10^{-4} \mathrm{~Pa}$ ) of the surrounding atmosphere [Takei, 1978]. The content of ferric ions in the present crystals was determined to be less than $0.3 \%$ by chemical analysis. The bulk density of $4.393 \mathrm{Mg} \mathrm{m}^{-3}$ measured by the Archimedean method was in close agreement with the measured $\mathrm{X}$ ray density of $4.392 \mathrm{Mg} \mathrm{m}^{-3}$. Lattice parameters measured at room temperature are $a_{0}=0.48218 \mathrm{~nm}, b_{0}=1.04814 \mathrm{~nm}$, and $c_{0}=0.60977 \mathrm{~nm}$. The microscopic observation of thin sections revealed no precipitated impurities within the crystals. Synthetic crystals, grown along the [001] direction, have a typical dimension of 6-7 $\mathrm{mm}$ in diameter and 6-8 $\mathrm{cm}$ in length. Disc-shaped specimens, about 1-2 mm in thickness, were cut from the boule, perpendicularly to the growth direction. Specimens were carefully polished on both parallel faces in order to give a good electrical contact with the driver plate and the electrode. The conductivity measured by dc method at room temperature and $1 \mathrm{~atm}$ pressure was found to be $5 \times 10^{-10}$ $\mathbf{S} / \mathbf{m}$.

The impact shock experiments were conducted using the double-stage light gas gun, HS-2, of Tokyo Institute of Technology. The projectile, $20 \mathrm{~mm}$ in diameter, consists of a highdensity polyethylene base with a $1.5-\mathrm{mm}$-thick copper flyer plate. The impact velocities of the flyer plate were measured by the magnetoflyer method [Kondo et al., 1977]. Precision in velocity measurements is estimated to be within $1 \%$. The flyer plate tilt angle upon impact was found to be less than $1^{\circ}$, using the pin-contactor method.

The conductivity experiments were performed by using the longitudinal arrangement, in which current flows parallel to the shock propagation direction, as is shown in Figure la. The specimen was mounted between a copper driver plate $(1.5 \mathrm{~mm}$ thick) and a cylindrical copper backing electrode (4-5 $\mathrm{mm}$ in diameter and several millimeters in height). A small amount 
a)

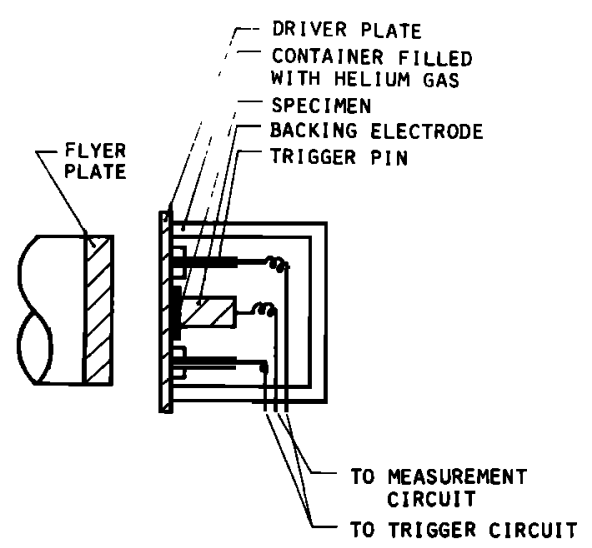

b)

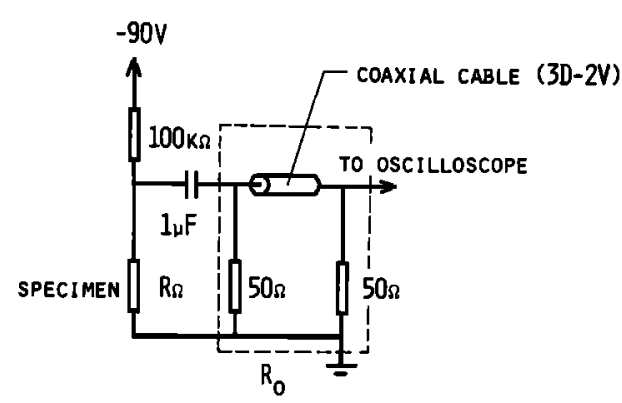

c)

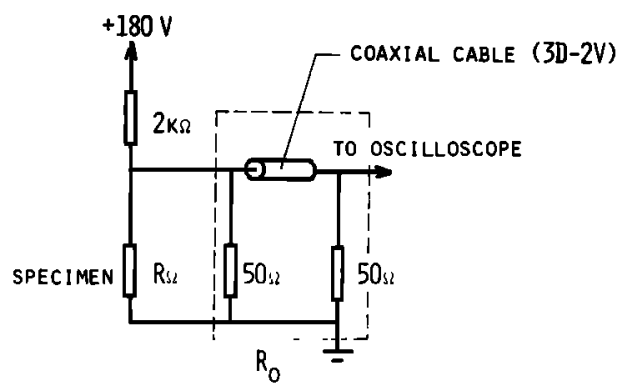

Fig. 1. (a) Experimental arrangement for the electrical conductivity measurements. (b) Electrical circuit for condenser charge method. (c) Electrical circuit for constant current method.

of conducting silver paste was applied to the driver-specimen and specimen-electrode interfaces to obtain better electrical contacts. The condenser charge method [Ahrens, 1966] was used for measurements in the low-conductance range $\left(\sim 10^{-4}\right.$ to $10^{-1}-\mathrm{S}$ range) as shown in Figure $1 b$. A constant current circuit (Figure $1 c$ ) was used for measurement of conductances greater than $10^{-1} \mathrm{~S}$. Oscilloscopes were triggered by one of two redundant coaxial shorting pins placed on both sides of the specimen (Figure 1a). To exclude the possibility that the observed decrease in resistivity could result from ionized air around the shocked specimen, the specimen assembly was placed in a pure helium atmosphere. The partial pressure of oxygen was estimated to be about $1 \mathrm{~Pa}$.

The shock state produced in the driver-target and flyer plate was determined from the measured flyer plate velocity and the Hugoniot of copper by using the impedance matching method [Rice et al., 1958; McQueen et al., 1970]. No Hugoniot measurements of fayalite were planned in the present study. Reported Hugoniot data for natural fayalite [McQueen and Marsh, 1966] were used for estimating the pressure achieved in the fayalite specimens (Figure 2). For a lower pressure range below the observed phase transition near $30 \mathrm{GPa}$ a the- oretical Hugoniot of fayalite was constructed by using the Birch-Murnaghan equation of state with the measured elastic parameters [Yagi et al., 1975] (Figure 2). Although the small temperature increase during shock compression and the elastic-plastic effect was neglected in the calculation, the calculated Hugoniot was found to be consistent with the observed shock data, as is shown in Figure 2.

An example of the determination of the shock state in an experiment on fayalite is given in Figure 2. Upon impact of the flyer plate on the target a shock is driven into the driver plate, which, in turn, propagates into the sample. The first shock state induced in the specimen by the shock wave is indicated as 1 in Figure 2. Upon the shock arrival at the specimen-electrode boundary a reflected shock propagates rearward in the specimen and brings it to the second shock state 2. Because of the higher shock impedance of copper as compared to fayalite the pressure of the reflected shock is higher than that of the first shock (see Figure 2). We have assumed that the Hugoniot of fayalite centered at shock state 1 is similar to the Hugoniot centered at zero pressure. Shock state conditions for each experiment are summarized in Table 1.

The shock temperatures (Table 1) were calculated on the basis of the method proposed by Walsh and Christian [1955]. Above about $40 \mathrm{GPa}$ the effect of the phase transition (de-

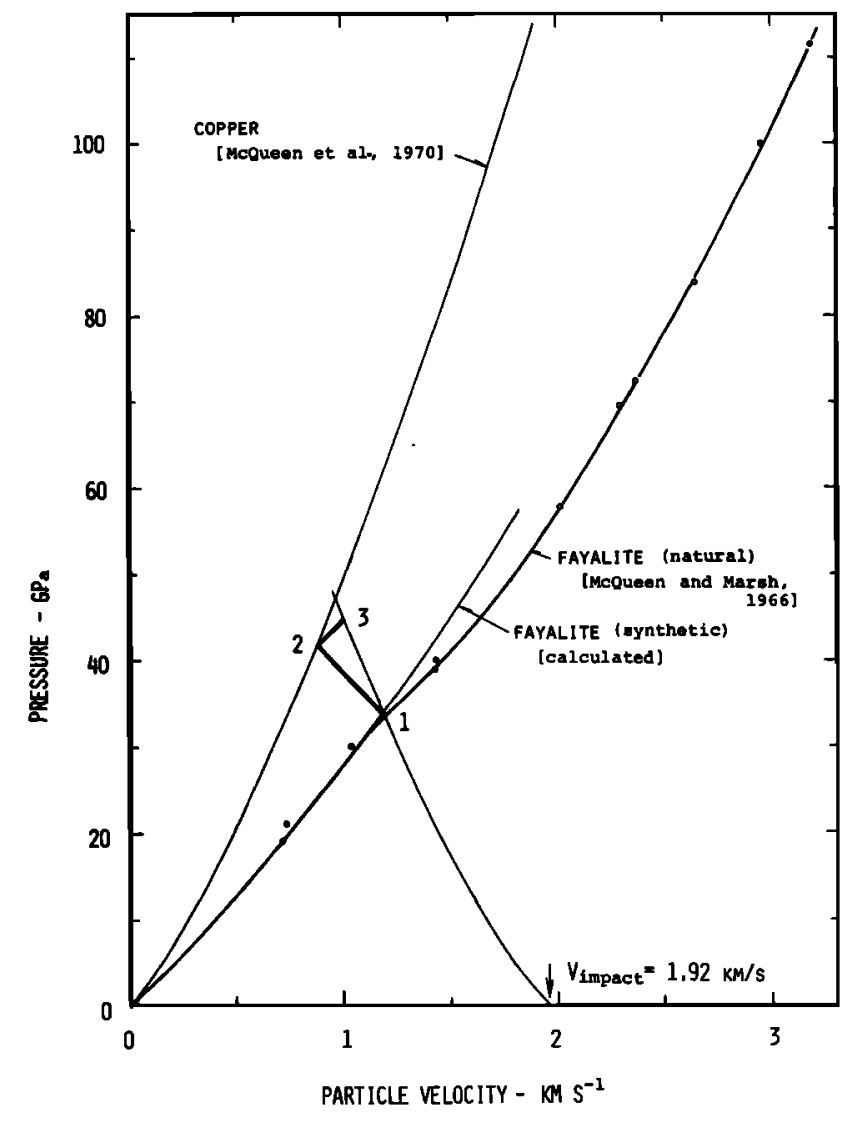

Fig. 2. Hugoniot of fayalite and graphical representation of the impedance-matching method in the pressure-particle velocity plane. Shock compression data of natural fayalite from Rockport, Massachusetts, were determined by McQueen and Marsh [1966] (open circles). (Solid circles are data cited by Davies and Gaffney [1973].) The calculated Hugoniot of fayalite is based on the elastic parameters determined by Yagi et al. [1975] $\left(K_{0}=1.25 \mathrm{Mbar}\right.$ and $\left.K^{\prime}=5\right)$. Heavy lines indicate the shock state produced via reflection of the shock wave from the fayalite-copper interface (shot 106). Shock states 1 and 2 correspond to the states denoted by A-B and B-C in Figures 3 and 4, respectively. 
TABLE 1. Conductivity of Fayalite Under Shock Compression

\begin{tabular}{|c|c|c|c|c|c|c|c|c|}
\hline Shot & $\begin{array}{l}\text { Impact } \\
\text { Velocity, } \\
\text { km/s }\end{array}$ & $\begin{array}{l}\text { Shock } \\
\text { Pressure,* } \\
\text { GPa }\end{array}$ & $\begin{array}{c}\text { Initial } \\
\text { Specimen } \\
\text { Thickness, } \\
\text { mm }\end{array}$ & $\begin{array}{l}\text { Shock- } \\
\text { Induced } \\
\text { Voltage, V }\end{array}$ & $\begin{array}{c}\text { Conductance, } \\
\mathbf{S}\end{array}$ & $\begin{array}{c}\text { Specific } \\
\text { Conductivity, } \\
\text { S/m }\end{array}$ & $\begin{array}{c}\text { Shock } \\
\text { Temperature, } \dagger \\
\text { K }\end{array}$ & Remarks \\
\hline \multicolumn{9}{|c|}{ Condenser Charge Method } \\
\hline 113 & $1.20 \pm 0.01$ & $\begin{array}{l}19.5(1) \\
25.0(2)\end{array}$ & 1.42 & $\begin{array}{l}0.61 \pm 0.04 \\
0.44 \pm 0.04\end{array}$ & $\begin{array}{l}(2.7 \pm 0.2) \times 10^{-4} \\
(2.0 \pm 0.3) \times 10^{-4}\end{array}$ & $\begin{array}{l}(2.7 \pm 0.2) \times 10^{-2} \\
(2.2 \pm 0.3) \times 10^{-1}\end{array}$ & 390 & \multirow{3}{*}{$\begin{array}{l}\text { diameter of } \\
\text { electrode is } \\
5.00 \mathrm{~mm} \neq\end{array}$} \\
\hline 107 & $1.56 \pm 0.02$ & $\begin{array}{l}26.0(1) \\
32.0(2)\end{array}$ & 1.35 & $\begin{array}{l}5.0 \pm 0.6 \\
4.8 \pm 0.6\end{array}$ & $\begin{array}{l}(2.4 \pm 0.4) \times 10^{-3} \\
(2.3 \pm 0.5) \times 10^{-3}\end{array}$ & $\begin{array}{l}(1.1 \pm 0.3) \times 10^{-1} \\
(5.8 \pm 1.2) \times 10^{-1}\end{array}$ & 430 & \\
\hline 106 & $1.92 \pm 0.02$ & $\begin{array}{l}33.0(1) \\
42.0(2)\end{array}$ & 1.10 & $\begin{array}{l}30 \pm 1.2 \\
74 \pm 1.2\end{array}$ & $\begin{array}{l}(2.0 \pm 0.7) \times 10^{-2} \\
(1.9 \pm 0.2) \times 10^{-1}\end{array}$ & $\begin{array}{l}(1.4 \pm 0.5) \times 10^{0} \\
(6.2 \pm 0.6) \times 10^{1}\end{array}$ & 480 & \\
\hline $106^{\prime}$ & $1.92 \pm 0.02$ & $\begin{array}{l}33.0(1) \\
42.0(2)\end{array}$ & 1.10 & $\begin{array}{l}33 \pm 2.0 \\
62 \pm 2.0\end{array}$ & $\begin{array}{l}(2.3 \pm 0.3) \times 10^{-2} \\
(8.9 \pm 1.2) \times 10^{-2}\end{array}$ & $\begin{array}{l}(1.7 \pm 0.2) \times 10^{0} \\
(3.0 \pm 0.4) \times 10^{1}\end{array}$ & 480 & \multirow[t]{3}{*}{$\begin{array}{l}\text { without silver } \\
\text { conducting } \\
\text { paste§ }\end{array}$} \\
\hline 108 & $2.19 \pm 0.02$ & $\begin{array}{l}38.0(1) \\
49.0(2)\end{array}$ & 1.33 & $\begin{array}{l}57 \pm 1.2 \\
76 \pm 1.2\end{array}$ & $\begin{array}{l}(6.9 \pm 0.4) \times 10^{-2} \\
(2.2 \pm 0.2) \times 10^{-1}\end{array}$ & $\begin{array}{l}(5.9 \pm 0.4) \times 10^{0} \\
(1.5 \pm 0.2) \times 10^{2}\end{array}$ & $(560)$ & \\
\hline 105 & $2.42 \pm 0.02$ & $\begin{array}{l}42.0(1) \\
56.0(2)\end{array}$ & 1.09 & $\begin{array}{l}83 \pm 1.6 \\
83 \pm 1.6\end{array}$ & $\begin{array}{l}(4.8 \pm 1.5) \times 10^{-1} \\
(4.8 \pm 1.5) \times 10^{-1}\end{array}$ & $\begin{array}{l}(3.3 \pm 1.0) \times 10^{1} \\
(1.5 \pm 0.5) \times 10^{2}\end{array}$ & $(720)$ & \\
\hline $\begin{array}{l}126 \\
129 \\
123 \\
135\end{array}$ & $\begin{array}{l}2.30 \pm 0.02 \\
2.34 \pm 0.02 \\
2.74 \pm 0.03 \\
3.02 \pm 0.03\end{array}$ & $\begin{array}{l}40.0(1) \\
41.0(1) \\
49.0(1) \\
55.0(1)\end{array}$ & $\begin{array}{l}0.90 \\
1.44 \\
0.90 \\
1.44\end{array}$ & $\begin{array}{l}\quad \text { Con } \\
0.1 \pm 0.02 \\
0.6 \pm 0.04 \\
0.1 \pm 0.04 \\
0.4 \pm 0.1\end{array}$ & $\begin{array}{l}\text { tant Current Method } \\
(8.6 \pm 2.3) \times 10^{-1} \\
(3.6 \pm 0.4) \times 10^{-1} \\
(8.6 \pm 6.0) \times 10^{-1} \\
(5.6 \pm 2.0) \times 10^{-1}\end{array}$ & $\begin{array}{l}(5.1 \pm 1.3) \times 10^{2} \\
(3.2 \pm 0.4) \times 10^{2} \\
(4.7 \pm 1.3) \times 10^{2} \\
(4.6 \pm 1.7) \times 10^{2}\end{array}$ & $\begin{array}{r}(650) \\
(680) \\
(960) \\
(1160)\end{array}$ & $\begin{array}{l}0.09 \mathrm{~A} \\
0.24 \mathrm{~A} \\
0.09 \mathrm{~A} \\
0.24 \mathrm{~A}\end{array}$ \\
\hline
\end{tabular}

In the condenser charge method the applied voltage is $90 \mathrm{~V}$. For the constant current method the applied current is given in the last column.

"The first shock state is indicated by (1), and the reverberated shock state by (2).

†Values in parentheses indicate the temperature calculations where the effect of phase transition to $2 \mathrm{FeO}+\mathrm{SiO}_{2}$ was taken into consideration.

¥Diameter of electrode is $4.00 \mathrm{~mm}$ unless otherwise stated.

$\$ \mathrm{~A}$ small amount of conducting silver paste is applied on the specimen surfaces unless otherwise stated.

composition reaction to $2 \mathrm{FeO}+\mathrm{SiO}_{2}$ (stishovite) was tentatively assumed) was taken into consideration, where the increase of the internal energy at the standard state was estimated from the difference of free energy and entropy between $\mathrm{Fe}_{2} \mathrm{SiO}_{4}$ (olivine) and $2 \mathrm{FeO}+\mathrm{SiO}_{2}$ (stishovite) [Mao et al., 1969; Mashimo et al., 1980].

\section{RESULTS AND DISCUSSION}

Voltage-time profiles for dynamic conductivity measurements obtained with the condenser charge method, when the impact velocities were $1.56 \pm 0.02,1.92 \pm 0.02$, and $2.42 \pm$ $0.02 \mathrm{~km} / \mathrm{s}$, are shown in Figures $3 a-3 c$. The first shock wave enters the specimen at time A (Figure $4 b$ ), when oscilloscopes are triggered nearly simultaneously. The first voltage signal at $B$ is due to the arrival of the shock wave at the specimen-electrode boundary, and the whole specimen is brought into a conducting state. The effective area for conduction is B-B' because of the rarefaction wave originated from the margin of the electrode B-B' (Figure 4a). The shock transit time between $A$ and $B$ is in reasonable agreement with the estimated reflected shock velocity inferred from the known Hugoniot data. Upon reflection of the shock wave from the electrode back into the specimen the specimen is shocked to a higher pressure state and, accordingly, a higher conductivity state, as is revealed in the increased voltage signal at $C$, where the reflected shock wave arrives at the driver-specimen boundary. The effective conducting area is now decreased to $C-C^{\prime}$. Subsequent shocks are considered to be disturbed owing to the interaction with the rarefaction waves before the shock rearrival on the specimen-electrode boundary, and therefore later signals were not utilized in the conductivity analysis. In the present analysis, voltage signals of $V_{B}$ and $V_{C}$ were taken as representing the conductivity of the first and second shock states, states 1 and 2 , respectively, and the specific conductivity is obtained from

$$
\sigma=\frac{L}{A R_{0}}\left(\frac{V_{x}}{V_{0}-V_{x}}\right)
$$

where $V_{x}$ is the observed voltage on the oscilloscope, $V_{0}$ is the applied voltage, $R_{0}$ is the effective resistance in parallel with the specimen (including cable termination), and $L$ and $A$ are the specimen thickness in the compressed state and effective area of the specimen, respectively. The value for the effective conduction area $\boldsymbol{A}$ is tentatively estimated from assuming lateral release waves at $45^{\circ}$ with respect to the direction of shock propagation. The value thus obtained for the second shock state could be underestimated, since the lateral release waves generally occur at angles larger than $45^{\circ}$.

Figure $5 a$ shows the voltage-time profile observed by the constant current $(0.09 \mathrm{~A})$ method when the impact velocity is $2.30 \pm 0.02 \mathrm{~km} / \mathrm{s}$. The initial voltage $V_{0}$, across the matching resistance of $25 \Omega$ of $2.25 \mathrm{~V}$, abruptly decreases at the time $\mathrm{A}$, when the shock wave arrives at the specimen-electrode boundary and the specimen becomes conducting. From the observed voltage $V_{x}$, indicated in the figure, the conductance of the specimen, $S$, is calculated to be

$$
S=\left(2.25-V_{x}\right) / 25 V_{x}
$$

Results of the electrical conductivity measurements are summarized in Figure 6 and Table 1 . As can be seen by inspecting Table 1 , in the condenser charge experiments the specific conductivity immediately after shock transit (state B in Figure 4) is smaller by a factor from 4.3 (shot 105) to 47 (shot 106) than that achieved via a second shock reflection (state $C$ in Figure 4). This increase in specific conductivity agrees remarkably well with the increase in conductivity inferred from just single-shock data. The electric conductivity of fayalite in- 
a) $\# 113$

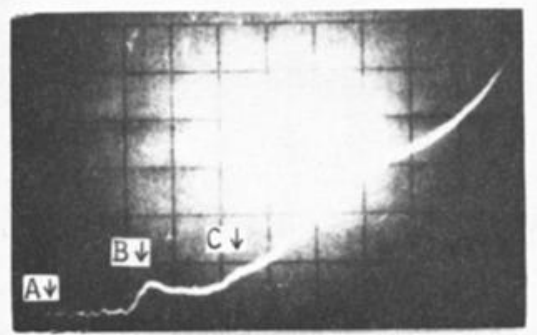

horizontal, $100 \mathrm{~ns} / \mathrm{div}$. vertical, $1 \mathrm{v} / \mathrm{div}$.

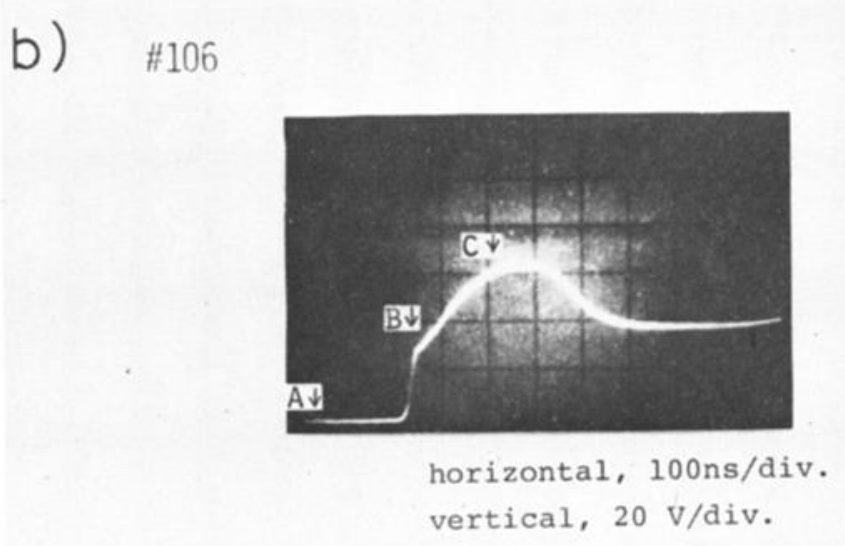

C) $\# 105$

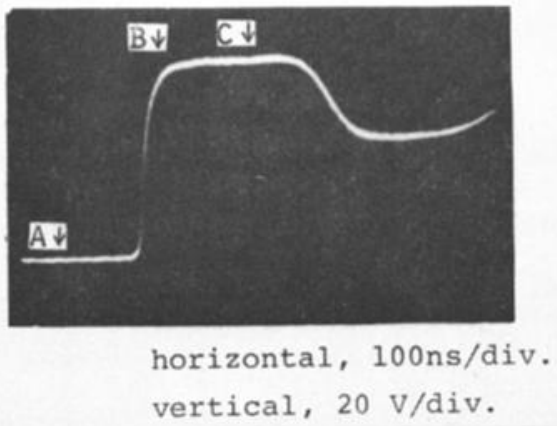

Fig. 3. Voltage-time profiles of dynamic conductivity measurements by the condenser charge method. A and B indicate the time of shock arrival on the driver plate-specimen interface and the specimen-electrode boundary. $C$ is the arrival time of the reverberated shock on the specimen-driver plate boundary. (a) Shot 113: impact velocity $=1.20 \pm 0.01 \mathrm{~km} / \mathrm{s}, P_{B}=195 \mathrm{kbar}$, and $P_{c}=250 \mathrm{kbar}$. (b) Shot 106: impact velocity $=1.92 \pm 0.02 \mathrm{~km} / \mathrm{s}, P_{B}=330 \mathrm{kbar}$, and $P_{C}$ $=420 \mathrm{kbar}$. $(c)$ Shot 105: impact velocity $=2.42 \pm 0.02 \mathrm{~km} / \mathrm{s}, P_{B}=$ $420 \mathrm{kbar}$, and $P_{c}=560 \mathrm{kbar}$.

creases with increasing pressure by a factor of about $10^{3}$ from 20 to $40 \mathrm{GPa}$. The specific conductivity data over the range from 19.5 to $42 \mathrm{GPa}$ can be closely fitted with a semilogarithmic relation

$$
\log _{10} \sigma(\mathrm{S} / \mathrm{m})=-4.65+0.15 P(\mathrm{GPa})
$$

The conductivity increase apparently becomes less rapid above about $40 \mathrm{GPa}$, and the conductivity remains at about $10^{2} \mathrm{~S} / \mathrm{m}$ to $56 \mathrm{GPa}$.
Although a change in the slope of the fayalite Hugoniot is clearly seen around $30 \mathrm{GPa}$, indicating a phase transformation, no particular anomaly was obtained in the conductivity versus pressure plot (Figure 6). A two-wave structure accompanied by the phase transformation was not detected in the voltage-time trace in the conductivity measurement.

In order to compare the present dynamic conductivity results with the static data the effect of the temperature increase during shock compression on the electrical conductivity must be corrected. In the correction procedure the pressure dependence of the activation energy of the electrical conductivity of olivine reported by Bradley et al. [1964] and Hamilton [1965] was taken into consideration. All the presently available data on the activation energy of pure fayalite are plotted in Figure 7 [Bradley et al., 1964; Akimoto and Fujisawa, 1965; Mao and Bell, 1972]. A systematic decrease of the activation energy with increasing pressure is clearly seen. This is reasonably understood from the consideration that the decrease in interatomic distance caused by pressure would lower the potential barrier for the electron hopping among neighboring iron ions. In the present analysis the activation energy at high-pressure regions was estimated by extrapolation as indicated in Figure 7. Thus at each value of compression we assume a single value of activation enthalpy, independent of temperature. By using the estimated activation energy and the calculated temperature increase during the shock compression (see Table 1) the dynamic conductivity data were reduced to an isothermal curve as shown by a dash-dotted line in Figure 6 .

The present analysis shows that the observed conductivity increase in dynamic measurements is predominantly caused by pressure. The general trend of the conductivity versus pressure in dynamic measurements is in remarkable agreement with the static measurements by Mao and Bell [1972]. A similar conductivity increase under shock loading has been found in some transition metal oxides, such as $\mathrm{MnO}$ and $\mathrm{CoO}$ [Syono et al., 1975]. However, the leveling off at high conductivities takes place at lower pressures in fayalite than in $\mathrm{MnO}$ and $\mathrm{CoO}$. On the other hand, no appreciable conductivity increase has been reported for nontransition metal oxides such as $\mathrm{MgO}$ and $\mathrm{Al}_{2} \mathrm{O}_{3}$ up to several tens of gigapascals. In the present study, dummy experiments of iron-doped $\mathrm{MgO}$ crystals $(\sim 0.25 \mathrm{wt} \% \mathrm{FeO})$ were also carried out up to about $50 \mathrm{GPa}$. No shock conduction signals were detected in this pressure range. Similarly, no large increase of absorptivity at short wavelengths was observed in the optical absorption experiments on the same $\mathrm{Fe}^{2+}$-containing $\mathrm{MgO}$ crystals [Goto et al., 1980]. According to Mao [1976], olivine containing less than $10 \mathrm{~mol} \%$ fayalite does not show strong absorptivity in the blue at high pressures. The observed drastic increase in conductivity under shock compression might be peculiar to the oxides with a high concentration of transition metal ions.

It is to be noted that at ambient condition the present single-crystal specimen is about 5 orders of magnitude less conductive than the polycrystalline fayalite used by Mao and Bell [1972], while the conductivities of both specimens show rather similar trends at high pressures. The conduction mechanism in ionic compounds under shock-compressed state is not fully understood yet. However, a large number of crystal defects introduced by shock deformation, specifically during elastic-plastic transition, would provide an abundant source of carriers in favor of the enhancement of conduction. This may partially explain why the initial difference in conductivities of our specimen and Mao and Bell's almost vanishes at high pressures. The agreement between pressure trends of the 
a)

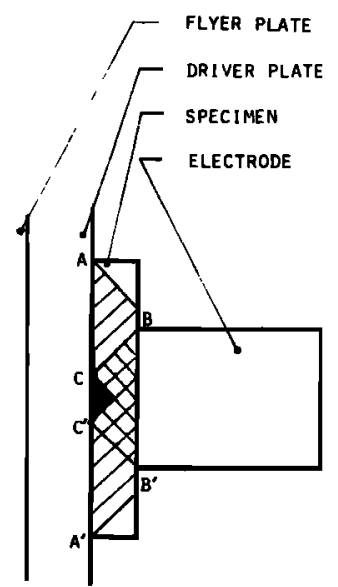

b)

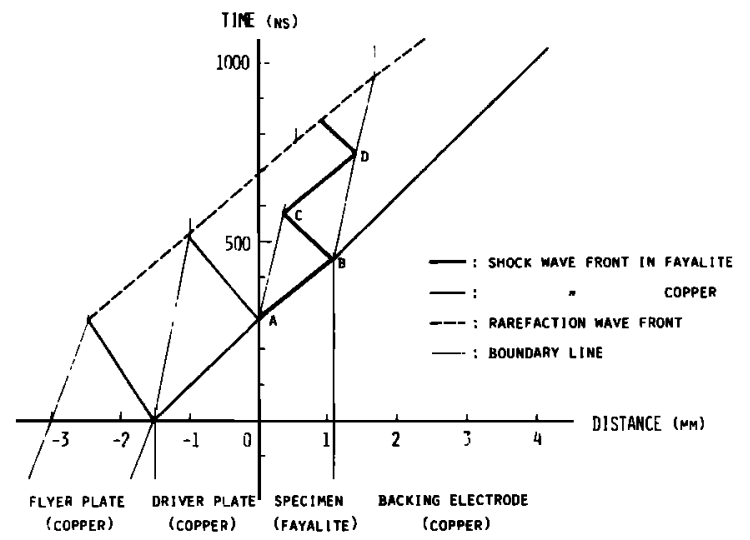

Fig. 4. (a) Illustration of the shock compression state realized in the present arrangement. $A B\left(A^{\prime} B^{\prime}\right)$ and $B^{\prime} C\left(B^{\prime} C^{\prime}\right)$ show rarefaction cones originated from the specimen rim $\left(A-A^{\prime}\right)$ at time $A$ and from the electrode rim $\left(\mathbf{B B}^{\prime}\right)$ at time $B$, respectively. (b) Schematic distance-time profile of shock propagation in the specimen assembly (shot 106).

shock and static conductivity measurements is not likely to be completely fortuitous. The decrease in the interatomic distance under high pressure might play a more important role in determining the conductivity. Most probably, the conductivity increase at high pressures observed here is related to the charge transfer process involving transition metal ions [Mao and Bell, 1972].

The steep conductivity increase around the depth of $400 \mathrm{~km}$ in the earth's mantle, obtained from studies of induction caused by magnetic disturbances [Rikitake, 1966; Banks, 1969], has been interpreted to be due to the olivine-spinel transformation [Akimoto and Fujisawa, 1965]. However, the drastic increase in conductivity with increasing pressure, as was demonstrated in the present study, might also be relevant to the earth's mantle. Olivine is not stable in the lower mantle. However, pressure enhancement of the charge transfer process seems to be more or less generally observed for most mantle minerals containing substantial amounts of transition metal ions [Mao, 1976]. Since the lower mantle is believed to consist of $\mathrm{MgSiO}_{3}$ perovskite plus periclase [Liu, 1976; Yagi et al., 1977; Ito and Matsui, 1978], the mode of iron partitioning between coexisting mantle phases such as $\mathrm{MgSiO}_{3}$ perovskite and periclase is quite important for the understanding of the transport properties in the mantle.

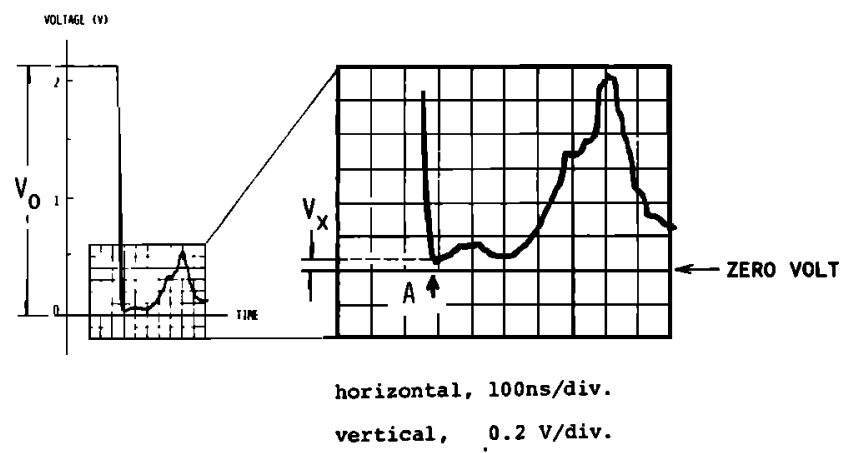

Fig. 5. Voltage-time profile of dynamic conductivity measurements by the constant current method (shot 126: impact velocity $=$ $2.30 \pm 0.02 \mathrm{~km} / \mathrm{s}$ and $P=650 \mathrm{kbar}$ ). The insert illustrates how the voltage changes with the arrival of the shock wave on the specimenelectrode boundary indicated by $A$. $V_{0}$ is the voltage induced by the constant current through the matching resistance of $25 \Omega$ (see Figure $1 c) . V_{x}$ is the voltage induced by the onset of conduction through the specimen.

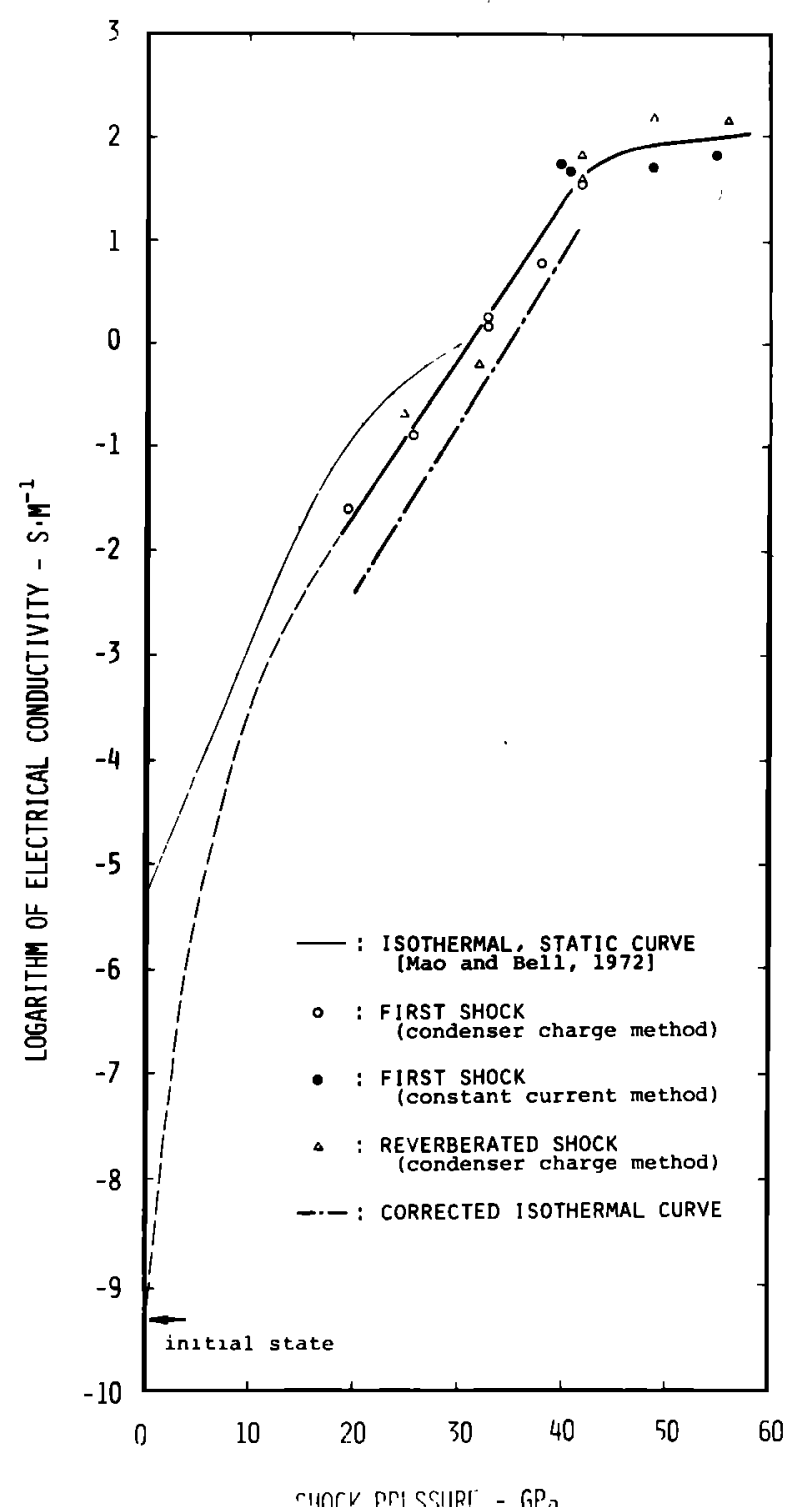

Fig. 6. Electrical conductivity of fayalite versus pressure. Measurements by Mao and Bell [1972] were conducted at room temperature, whereas data obtained in the shock compression experiments varied from 360 to $1160 \mathrm{~K}$ with increasing pressure. 


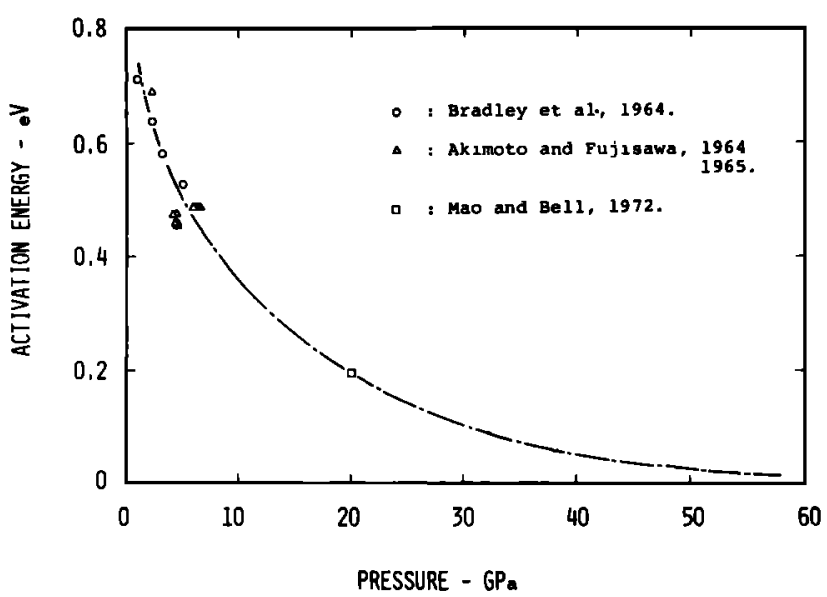

Fig. 7. Observed pressure dependence of activation energy in fayalite. The corrected isothermal curve (Figure 6 ) was calculated by using the activation energy versus pressure relation indicated in this figure. (The activation energy data by Akomoto and Fujisawa [1965] were partly from Akimoto and Fujisawa [1964].)

Acknowledgments. The authors appreciate the interest and encouragement proffered by S. Saito and $Y$. Nakagawa in carrying out this research. They are indebted to $T$. Goto for helpful discussions. The work was partially supported under the Japan-U. S. Cooperative Science Program: Y.S. and T.J.A. are grateful for the support from the Japan Society for the Promotion of Science (grant 4R 032) and U.S. National Science Foundation (grants DES 75-15006 and FJ 4035). Contribution 3056, Division of Geological and Planetary Sciences, California Institute of Technology.

\section{REFERENCES}

Ahrens, T. J., High-pressure electrical behavior and equation of state of magnesium oxide from shock wave measurements, J. Appl. Phys., 37, 2532-2541, 1966.

Akimoto, S., and H. Fujisawa, Demonstration of the electrical conductivity jump produced by the olivine-spinel transition, Tech. Rep. 135, Inst. for Solid State Phys., Univ. of Tokyo, Tokyo, 1964.

Akimoto, S., and H. Fujisawa, Demonstration of the electrical conductivity jump produced by the olivine-spinel transition, $J$. Geophys. Res., 70, 443-449, 1965.

Banks, R. J., Geomagnetic variations and the electrical conductivity of the upper mantle, Geophys. J. Roy. Astron. Soc., 17, 457-489, 1969.

Bradley, R. S., A. K. Jamil, and D. C. Munro, The electrical conductivity of olivine at high temperatures and pressures, Geochim. Cosmochim. Acta, 28, 1669-1678, 1964.

Davies, G. F., and E. S. Gaffiney, Identification of high-pressure phase of rocks and minerals from Hugoniot data, Geophys. J. Roy. Astron. Soc., 33, 165-183, 1973.

Duba, A., and I. A. Nicholls, The influence of oxidation state on the electrical conductivity of olivine, Earth Planet. Sci. Lett., 18, 59-64, 1973.

Goto, T., T. J. Ahrens, G. R. Rossman, and Y. Syono, Optical absorbance of $\mathrm{Fe}^{+2}$-doped magnesium oxide under shock compression, Phys. Earth Planet. Interiors, in press, 1980.
Hamilton, M., Temperature variation at constant pressures of the electrical conductivity of periclase and olivine, J. Geophys. Res., 70, 5679-5692, 1965.

Ito, E., and Y. Matsui, Synthesis and crystal-chemical characterization of $\mathrm{MgSiO}_{3}$ perovskite, Earth Planet. Sci. Lett., 38, 443-450, 1978.

Kondo, K., A. Sawaoka, and S. Saito, Magnetoflyer method for measuring gas-gun projectile velocities, Rev. Sci. Instrum., 48, 1581$1582,1977$.

Liu, L., Orthorhombic perovskite phases observed in olivine pyroxene and garnet at high pressures and temperatures, Phys. Earth Planet. Interiors, 11, 289-298, 1976.

Mao, H. K., Charge-transfer processes at high pressure, in The Physics and Chemistry of Minerals and Rocks, edited by R. G. J. Strens, pp. 573-581, John Wiley, New York, 1976.

Mao, H. K., and P. M. Bell, Electrical conductivity and red shift of absorption in olivine and spinel at high pressure, Science, 176, 403406, 1972.

Mao, H. K., T. Takahashi, W. A. Bassett, J. S. Weaver, and S. Akimoto, Effect of pressure and temperature on the molar volumes of wüstite and of three $(\mathrm{Fe}, \mathrm{Mg})_{2} \mathrm{SiO}_{4}$ spinel solid solutions, $J$. Geophys. Res., 74, 1061-1069, 1969.

Mashimo, T., T. Sōma, K. Nishii, A. Sawaoka, and S. Saito, Some physical properties of amorphous $\mathrm{SiO}_{2}$ synthesized by shock compression of $\alpha$-quartz, Phys. Chem. Miner., in press, 1980.

McQueen, R. G., and S. P. Marsh, Section 7: Compressibility, elastic constants (Table 7-14), in Handbook of Physical Constants, Mem. 97, edited by S. P. Clark, Jr., Geological Society of America, New York, 1966.

McQueen, R. G., S. P. Marsh, J. W. Taylor, J. N. Fitz, and W. J. Carter, The equation of state of solids from shock wave studies, $\mathrm{High}$ Velocity Impact Phenomena, edited by R. Kinslow, pp. 244-419, Academic, New York, 1970.

Rice, M. H., R. G. McQueen, and J. M. Walsh, Compression of solids by strong shock waves, Solid State Phys., 6, 1-63, 1958.

Rikitake, T., Electromagnetism and Earth Interior, Elsevier, New York, 1966.

Schulien, S., U. Hornemann, and D. Stöffler, Electrical conductivity of dunite during shock compression from 12.5 to $45 \mathrm{GPa}$, Geophys. Res. Lett., 5, 345-348, 1978.

Shankland, T. J., Electrical conduction in rocks and minerals: Parameters for interpretation, Phys. Earth Planet. Interiors, 10, 209-219, 1975.

Syono, Y., T. Goto, J. Nakai, and Y. Nakagawa, Shock compression study of transition metal oxides, Proc. Int. Conf. High Pressure 4th, 466-472, 1975.

Takei, $\mathrm{H}$., Growth of fayalite $\left(\mathrm{Fe}_{2} \mathrm{SiO}_{4}\right)$ single crystals by the floatingzone method, J. Cryst. Growth, 43, 463-468, 1978.

Walsh, J. M., and R. G. Christian, Equation of state of metals from shock wave measurements, Phys. Rev., 97, 1544-1556, 1955.

Yagi, T., Y. Ida, Y. Sato, and S. Akimoto, Effect of hydrostatic pressure on the lattice parameters of $\mathrm{Fe}_{2} \mathrm{SiO}_{4}$ olivine up to $70 \mathrm{kbar}$, Phys. Earth Planer. Interiors, 10, 348-354, 1975.

Yagi, T., H. K. Mao, and P. M. Bell, Crystal structure of $\mathrm{MgSiO}_{3}$ perovskite, Carnegie Inst. Wash. Yearb., 76, 516-519, 1977.

(Received December 20, 1978; revised April 23, 1979; accepted January 4, 1980.) 